\title{
Clinical outcome of transfemoral embolisation in patients with arteriovenous malformations of the liver in hereditary haemorrhagic telangiectasia (Weber-Rendu-Osler disease)
}

M Caselitz, S Wagner, A Chavan, M Gebel, J S Bleck, A Wu, H J Schlitt, M Galanski, M P Manns

\begin{abstract}
Background-Arteriovenous malformations of the liver in Osler's disease may present as high output cardiac failure. A few case reports suggested that treatment with arterial embolisation may have beneficial effects in such patients.

Aims-To investigate the efficacy and safety of this treatment modality in a prospective pilot study.

Patients and methods-Four women and one man (aged 39-59 years) with the dominant hepatic manifestation of Osler's disease presented with symptoms of cardiac failure and elevated cardiac output. Arteriovenous malformations were treated in three to five sessions with arterial embolisation using coils. The outcome was analysed by measurement of cardiac output and scoring of clinical symptoms. Results-Embolisation was technically feasible in all patients and adequate occlusion of vascular malformations was achieved in four patients. After completion of therapy symptoms improved in four patients, while one patient suffered from abdominal pain due to cholangitis. One patient died seven months after the embolisation treatment from variceal bleeding. Mean cardiac output significantly decreased from 14.2 (range 12-17.3) $1 /$ min to 8 (range $5.9-10.6) 1 / \mathrm{min}(\mathrm{p}=0.043)$. After a median follow up of 23 months (range 7-50 months), three of five patients had a long lasting improvement of clinical symptoms and cardiac function.

Conclusions-This first treatment series of patients with dominant hepatic involvement in Osler's disease indicates that arterial embolisation may prevent cardiac failure by significantly lowering cardiac output.

(Gut 1998;42:123-126)
\end{abstract}

Abdominal Surgery

Medizinische

Hochschule, Hannover,

Germany

A Wu

H J Schlitt

Keywords: hereditary haemorrhagic telangiectasia; Weber-Rendu-Osler disease; hepatic vascular malformation; cardiac failure; embolisation therapy

Correspondence to: Professor Dr M P Manns, Department of

Gastroenterology and

Hepatology, Medical School, Carl Neuberg Strasse 1, 30623 Hannover, Germany.

Accepted for publication 31 July 1997
The larger vascular malformations are described as arteriovenous shunts, which can be found in any organ, but most often in the lungs, central nervous system, and digestive tract, especially the liver. ${ }^{1}$ Hepatic involvement is described in $8-31 \%$ of patients suffering from HHT. $^{23}$ The major pathological features are a so called "pseudocirrhosis" with abnormally dilatated vessels surrounded by a varying amount of stroma and arteriovenous malformations (AVM). ${ }^{4}$

Clinical symptoms are hepatomegaly and a bruit over the liver. Serum levels of $\gamma$-glutamyl transferase and alkaline phosphatase can be elevated. Clinical complications of the liver involvement depend on the anatomy of these shunts: malformations between the hepatic artery and the liver veins may lead to high output cardiac failure ${ }^{5}$ and malformations between the hepatic artery and the portal vein may cause portal hypertension. ${ }^{6}$

The treatment of arteriovenous malformations of the liver is usually conservative. This treatment may fail, however, in patients with large AVM. There is some experience with surgical ligation of the feeding vessels ${ }^{6}$ and liver transplantation. ${ }^{2}$ On the other hand, there are a few encouraging case reports of embolisation of the feeding vessels. ${ }^{6-10}$ In this pilot study we have prospectively investigated the clinical outcome of percutaneous embolisation in five patients with large arteriovenous malformations of the liver and symptoms of cardiac failure in HHT.

\section{Patients and methods}

PATIENTS

From 1991 to 1995 five consecutive patients with HHT and dominant hepatic arteriovenous malformations were included in this pilot study. All patients suffered from symptoms of cardiac failure and circulatory disturbance or complications of portal hypertension. HHT was diagnosed when at least two elements of the classic triad (mucocutaneous telangiectasia, epistaxis, and a family history of HHT) were present. The patients were screened for hepatic involvement by colour Doppler sonography and the hepatic vascular lesions were confirmed by angiography.

Table 1 summarises clinical details of the patients at referral. The group consisted of four women and one man with a mean age of 50 years (range 39-59 years). Mucocutaneous telangiectasia was present in all patients. Epistaxis was present in three patients and a positive is an autosomal dominantly transmitted malformation of vascular structure with diverse manifestations. The classic clinical features are mucocutaneous telangiectasia, epistaxis, and a family history of $\mathrm{HHT}^{1}$ 
Table 1 Clinical details of patients at referral

\begin{tabular}{|c|c|c|c|c|c|}
\hline & Patient 1 & Patient 2 & Patient 3 & Patient 4 & Patient 5 \\
\hline Sex & Female & Female & Female & Male & Female \\
\hline Age & 54 & 50 & 40 & 58 & 47 \\
\hline family history & + & + & + & + & - \\
\hline Telangiectasia & Face & Face & Face & Face & Face \\
\hline Epistaxis & - & - & + & + & + \\
\hline \multirow{6}{*}{$\begin{array}{l}\text { Clinical symptoms of } \\
\text { complications }\end{array}$} & Dyspnoea & Upper GI bleeding & Abdominal angina & Dyspnoea & Vitality decrease \\
\hline & Nycturia & $\begin{array}{l}\text { Left ventricular } \\
\text { hypertrophy }\end{array}$ & Weight loss & Nycturia & Dyspnoea \\
\hline & $\begin{array}{l}\text { Left ventricular } \\
\text { hypertrophy }\end{array}$ & Mitral insufficiency & $\begin{array}{l}\text { Tricuspidal } \\
\text { insufficiency }\end{array}$ & Vitality decrease & \\
\hline & Arrhythmia & Ascites & $\begin{array}{l}\text { Ventricular } \\
\text { extrasystoles }\end{array}$ & & \\
\hline & Hypertension & & $\begin{array}{l}\text { Congested jugular } \\
\text { veins }\end{array}$ & & \\
\hline & Ascites & & Steal syndrome & & \\
\hline Hepatomegaly & + & + & + & + & + \\
\hline Bruit over the liver & + & + & + & + & + \\
\hline $\begin{array}{l}\text { Alkaline phosphatase } \\
\text { raised }\end{array}$ & + & + & + & + & + \\
\hline GGT raised & + & + & + & + & + \\
\hline $\begin{array}{l}\text { Cardiac output } \\
\text { (1/min) before } \\
\text { therapy }\end{array}$ & 15 & 17,3 & 13 & 12 & 12.5 \\
\hline Shunt & Arteriovenous & Arterioportal & Arteriovenous & Arteriovenous & Arteriovenous \\
\hline $\begin{array}{l}\text { Number of } \\
\text { embolisations }\end{array}$ & 3 & 3 & 5 & 3 & 3 \\
\hline
\end{tabular}

family history was also found in three patients. There were clinical symptoms of chronic high output cardiac failure due to arteriovenous malformations in four patients. One patient suffered from arterioportal shunts, which led to complications of portal hypertension (ascites, gastrointestinal bleeding). Extrahepatic visceral involvement was detected in two patients. One patient had arteriovenous malformations around the right kidney and in the retroperitoneum. In another patient arteriovenous shunts and collateral vessels were detected in the mesentery. These mesenteric malformations led to symptoms of abdominal angina due to a steal syndrome.

All patients had anicteric cholestasis with elevation of $\gamma$-glutamyl transferase activity. Four patients had increased alkaline phosphatase activity. Cholinesterase levels and prothrombin time were normal in all patients. No signs of cirrhosis were found in any patient. All patients underwent right heart catheterisation and echocardiography before and after embolisation and at the end of follow up to measure cardiac output.

To assess the clinical benefit of arterial embolisation a clinical score was developed (table 2). The general symptoms (decrease in vitality, weight loss), abdominal symptoms (pain, ascites) and cardiac symptoms (nycturia, dyspnoea) were each graded. The decrease in vitality was classified according to a severity index $(0=$ no restrictions; $1=$ feeling of weariness; 2 = inability to work; 3 = hospitalisation). Weight loss and nycturia were also graded into four groups. The severity of pain was estimated and graded depending on the drugs required. Dyspnoea was classified according to the grading of the American Heart Association. Varicosis of the oesophagus was graded according to the classification of Paquet. ${ }^{11}$ The total clinical score (0-9) was calculated by obtaining the sum of the means of the symptom categories (general symptoms, abdominal symptoms, cardiac symptoms).

EMBOLISATION TECHNIQUE

All patients underwent three to five sessions of transfemoral arterial embolisation of hepatic vascular malformations. The procedures were performed over a period of 4-20 weeks. The intervention was carried out under local anaesthesia and intra-arterial analgesics were given when required.

Using a transfemoral approach an abdominal aortography was initially performed followed by indirect mesentericoportography over the superior mesenteric artery or splenic artery. The hepatic artery branches were selectively catheterised and the AVM were embolised

Table 2 Criteria for clinical score

\begin{tabular}{|c|c|c|c|c|}
\hline & \multicolumn{4}{|l|}{ Score } \\
\hline & 0 & 1 & 2 & 3 \\
\hline \multicolumn{5}{|l|}{ General symptoms } \\
\hline Decrease in vitality & No restrictions & Increased fatigue & Treated as outpatient & Treated in hospital \\
\hline $\begin{array}{l}\text { Loss of weight in patients } \\
\text { without ascites }\end{array}$ & None & $<2 \mathrm{~kg}$ & $<5 \mathrm{~kg}$ & $>5 \mathrm{~kg}$ \\
\hline \multicolumn{5}{|l|}{ Abdominal symptoms and findings } \\
\hline Abdominal pain & None & No analgesics necessary & Analgesics necessary & $\begin{array}{l}\text { Morphine like analgesics } \\
\text { necessary }\end{array}$ \\
\hline Ascites & None & Few & Moderate & Severe \\
\hline Oesophageal varices & None & Grade 1-2 & Grade 3 & Grade 4 \\
\hline \multicolumn{5}{|l|}{ Cardiac symptoms } \\
\hline Nycturia & None & $1-2$ & $2-3$ & $>3$ \\
\hline Dyspnoea & None & On strong exertion & On light exertion & At rest \\
\hline
\end{tabular}




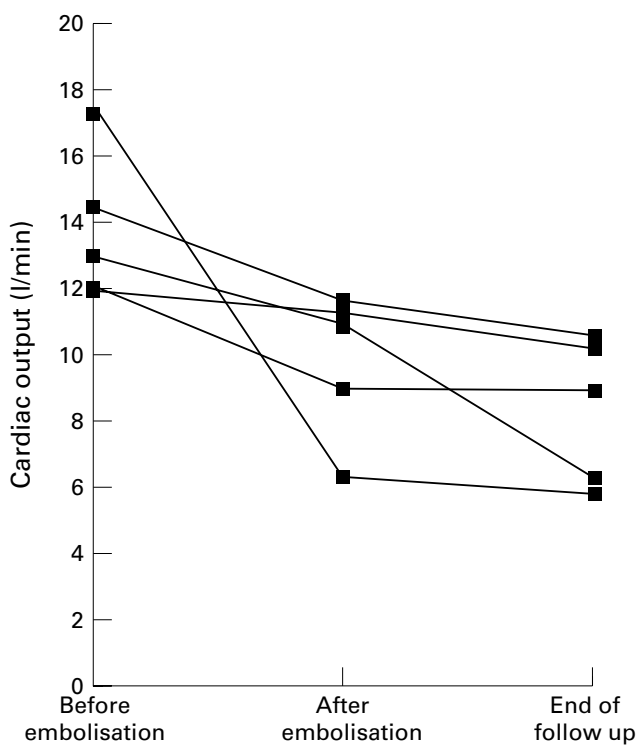

Figure 1 Comparison of cardiac output before and after embolisation and at the end of follow up.

peripherally with polyvinylalcohol particle coils (Ivalon, size 250-1180 $\mu \mathrm{m}$; Interventional Therapeutics Corporation; South San Francisco, CA, USA) followed by proximal embolisation of large feeding arteries using platinum or steel coils (2-8 $\mathrm{mm}$ in diameter; MReye William Cook Europe A/S, Bjaeverskov, Denmark). The extent of the embolisation and the material used varied according to the clinical findings, the vascular anatomy of the patient, and the results of previous treatments. The result of the embolisation was documented by angiography.

FOLLOW UP

Patients were followed for a median of 23 months (range 7-50 months) after the last embolisation. Cardiac output was measured by right heart catheterisation and echocardiography after completion of treatment and at the end of follow up. Response to treatment was statistically analysed by comparing clinical scores and cardiac output before treatment, after completion of treatment, and at the end of follow up using the Wilcoxon signed rank test to test for matched pairs.

\section{Results}

Selective embolisation of the hepatic vascular malformations was technically feasible in all patients and complete occlusion of the malformations was achieved in four patients. In one patient embolisation was incomplete.

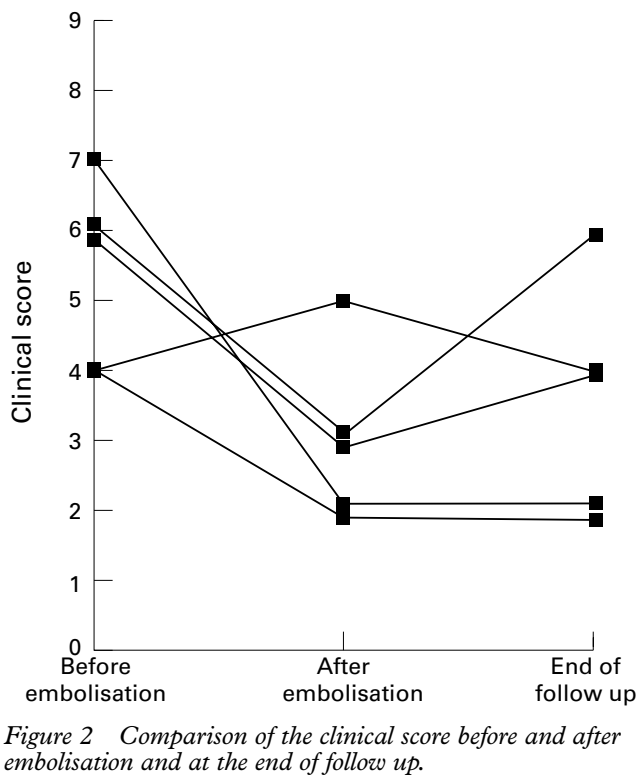

After completion of treatment mean cardiac output significantly decreased from 14.2 (range 12-17.3) $1 / \mathrm{min}$ to 9.8 (range 5.9-10.6) $1 / \mathrm{min}$. This significant decrease was maintained after median follow up of 23 months $(8 \mathrm{l} / \mathrm{min}$; $\mathrm{p}<0.05$ ) (fig 1).

After treatment, the clinical score decreased from $5.6(7-4)$ to $3(2-5)(p=0.078, N S)$ (fig 2) and remained virtually unchanged until the end of follow up (median 23 months). The treatment was well tolerated in four patients. Minor side effects were noted immediately after embolisation includingmoderate pain and nausea, which persisted for up to one to three days. They were controlled easily by analgesics and antiemetics. Laboratory tests showed a transient increase in leucocytes, alkaline phosphatase, and $\gamma$-glutamyl transferase. Serum concentrations of albumin and cholinesterase remained unchanged after embolisation.

There was an impressive improvement in clinical symptoms in the patient suffering from abdominal angina. After embolisation, body weight increased and analgesic treatment was discontinued.

One patient suffered from ischaemic cholecystitis and relapsing cholangitis with severe abdominal pain necessitating discontinuation of treatment. In this patient a reduction in cardiac output was not achieved immediately at the end of the embolisation, but during the follow up after 28 months.

Table 3 Review of the literature:transfemoral arterial hepatic embolisation in patients with HHT

\begin{tabular}{|c|c|c|c|c|c|c|}
\hline Authors & $\begin{array}{l}\text { Number of } \\
\text { patients }\end{array}$ & Age (y) & $\operatorname{Sex}$ & Shunt type & Number of embolisations & Follow up \\
\hline Zentler Munro et al ${ }^{6}$ & 1 & 51 & $M$ & Arterioportal & $\begin{array}{l}1 \text { (additional ligation } \\
\text { of the hepatic artery) }\end{array}$ & 6 months \\
\hline Derauf $e t a l^{8}$ & 1 & 48 & $\mathrm{~F}$ & Arteriovenous & $x^{2}+2-5$ & 2 months, stable \\
\hline \multirow[t]{2}{*}{ Göthlin et al } & 2 & 53 & $\mathrm{~F}$ & Arteriovenous & 2 & Died after 2 months \\
\hline & & 41 & $\mathrm{~F}$ & Arteriovenous & 1 & 24 months, stable \\
\hline Nikolopoulos $e t a l^{10}$ & 1 & 45 & $\mathrm{~F}$ & Arteriovenous & 1 & 84 months, stable \\
\hline Allison $e t a l^{12}$ & 1 & - & - & Arteriovenous & 1 & None \\
\hline Bourgeois et $a l^{13}$ & 1 & 66 & $\mathrm{~F}$ & Arteriovenous & 2 & Died after 3 weeks \\
\hline Brohee et al $l^{14}$ & 1 & 45 & $\mathrm{~F}$ & Arteriovenous & 2 & 24 months, stable \\
\hline Roman et al $l^{15}$ & 1 & 62 & $\mathrm{~F}$ & Arteriovenous & 1 & 2 months, stable \\
\hline Whiting et $a l^{16}$ & 1 & 71 & $\mathrm{~F}$ & Arteriovenous & 3 & None \\
\hline
\end{tabular}


One patient died seven months after the last embolisation. Her death was not related to the treatment. Although cardiac output had decreased from $17.3 \mathrm{l} / \mathrm{min}$ to $5.8 \mathrm{l} / \mathrm{min}$, portal hypertension recurred after temporary improvement. The patient was readmitted six months after the third embolisation due to critical bleeding from oesophageal varices.

\section{Discussion}

This study shows that the clinical course of HHT patients with dominant hepatic involvement and symptoms of cardiac decompensation can be favourably influenced by arterial embolisation. Embolisation therapy was technically feasible, safe, and minimally invasive in our patients. Our study confirms preliminary results obtained from recent case reports (table 3). ${ }^{6-10} 12-16$

The clinical course of hepatic involvement in patients with HHT depends on the anatomy of the vascular malformations. Shunting between the hepatic artery and hepatic veins may lead to high output cardiac failure ${ }^{5}$ and to a steal syndrome with symptoms of abdominal angina as shown in one of our patients. After embolisation the patient's symptoms improved remarkably, suggesting that a steal syndrome due to hepatic and mesenteric malformations can be treated efficiently by embolisation of branches of the hepatic artery.

Shunts between the hepatic artery and the portal vein occur rarely and may lead to portal hypertension. ${ }^{6}$ One patient (patient 3 ) in our study suffered from portal hypertension. Although a decrease in cardiac output from 17.3 $1 / \mathrm{min}$ to $5.9 \mathrm{l} / \mathrm{min}$ after embolisation was achieved, portal hypertension recurred soon after temporary improvement and led to critical bleeding from oesophageal varices. Similarly Zentler Munro et al described a patient with HHT suffering from portal hypertension due to arterioportal shunts in the liver. ${ }^{6}$ The patient was treated with embolisation and ligation of the hepatic artery. These few reported cases in the literature may indicate that portal hypertension due to arterioportal shunts in patients with HHT cannot be controlled adequately by arterial embolisation alone. A portovenous shunt seems to be contraindicated in these patients because it would increase the flow in the arterioportal shunt and thereby probably elevate the central venous blood pressure significantly in patients with symptoms of cardiac failure. For these patients liver transplantation may be the most promising treatment modality, presuming that vascular malformations are restricted to the liver.

In general, embolisation treatment was well tolerated. The most frequent side effects observed in our patients were nausea and abdominal pain in the upper right quadrant. The pain persisted for a few hours to up to three days after embolisation and responded to non-opiate analgesics and antiemetics. Similar experiences have been reported in the literature. ${ }^{8}$ A significant side effect was seen in one patient, who presented with ischaemic cholangitis and cholecystitis complicated by severe pain and nausea.
In the long run conservative treatment in patients with symptoms of cardiac failure due to dominant hepatic involvement may not be sufficient. Therefore, alternative therapeutic options must be considered. Various options for treatment are described including resection, ligation of the hepatic artery, ${ }^{67}$ and liver transplantation. ${ }^{2}$

In our patients we saw a long lasting effect of interventional treatment up to 50 months after the last embolisation. Nikolopoulos et al reported a single case, who remained stable over a period of seven years. ${ }^{10}$ Further investigations are required to confirm the stability of the long term results after arterial embolisation. Vascular malformations may potentially reappear and require further embolisations. In case of recurrent symptoms of heart failure in the long term a liver transplantation must be considered as alternative treatment. For primary management of these patients, however, arterial embolisation should probably be tried.

Since embolisation is far less invasive than liver transplantation, our study helps to establish embolisation as a treatment modality for these selected patients, which should be controlled in larger series.

Parts of this work were presented as a poster at the annual meeting of the German Association for the Study of the Liver (GASL) in Konstanz, Germany, January 1997.

1 Haitjema T, Westermann CJ, Overtoom TT, et al. Hereditary hemorrhagic telangiectasia (Osler-WeberRendu disease): new insights in pathogenesis, complications, and treatment. Arch Intern Med 1996;156:714-9.

2 Bauer T, Britton P, Lomas D, Wight DG, Friend PJ, Alexander GJ. Liver transplantation for hepatic arteriovenous malformation in hereditary haemorrhagic telangiectasia. F Hepatol 1995;22:586-90.

3 Reilly PJ, Nostrant TT. Clinical manifestations of hereditary hemorrhagic telangiectasia. Am $\mathcal{F}$ Gastroenterol 1984;79: 363-7.

4 Cooney T, Sweeney EC, Coll R, Greally M. "Pseudocirrhosis" in hereditary haemorrhagic telangiectasia. $\mathcal{F}$ Clin Pathol 1977;30:1134-41.

5 Bernard G, Mion F, Henry L, Plauchu H, Paliard P. Hepatic involvement in hereditary hemorrhagic telangiectasia: clinical, radiological, and hemodynamic studies of 11 cases. Clinical, radiological, and hemodynan

6 Zentler Munro PL, Howard ER, Karani J, Williams R. Variceal haemorrhage in hereditary haemorrhagic telangiectasia. Gut 1989;30:1293-7.

7 Radtke WE, Smith HC, Fulton RE, Adson MA. Misdiagnosis of atrial septal defect in patients with hereditary telangiectasia (Osler-Rendu-Weber disease) and hepatic arteriovenous fistulas. Am Heart f 1978;95:235-42.

8 Derauf BJ, Hunter DW, Cardella JW, Castaneda-Zuniga W, Amplatz K. Peripheral embolisation of diffuse hepatic arteriovenous malformations in a patient with hereditary hemorrhagic telangiectasia. Cardiovasc Intervent Radiol 1987; 12:236-7.

9 Göthlin JH, Nordgard K, Jonsson K, Nyman U. Hepatic telangiectasia in Osler's disease treated with arterial embolisation. Report of 2 cases. Eur f Radiol 1982;2:27-30.

10 Nikolopoulos N, Xynos E, Vassilakis JS. Familial occurrence of hyperdynamic circulation status due to intrahepatic of hyperdynamic circulation status due to intrahepatic
fistulae in hereditary hemorrhagic telangiectasia. Hepatofistulae in hereditary hemorrhagterology 1988;35:167-8.

11 Paquet KJ. Prophylactic endoscopic sclerosing treatment of the esophageal wall in varices-a prospective controlled randomized trial. Endoscopy 1982;14:4-5.

12 Allison DJ, Jordan H, Hennessy O. Therapeutic embolisation of the hepatic artery: a review of 75 procedures. Lancet 1985;i:595-9.

13 Bourgeois N, Delcour C, Deviere J, et al. Osler-Weber-Rendu disease associated with hepatic involvement and high output heart failure. F Clin Gastroenterol 1990;12:236-8.

14 Brohee D, Franken P, Fievez M, et al. High-output right ventricular failure secondary to hepatic arteriovenous microfistulae. Selective arterial embolisation treatment. Arch Intern Med 1984;144:1282-4.

15 Roman CF, Do Cha S, Incarvito J, Cope C, Maranhao V. Transcatheter embolisation of hepatic arteriovenous fistula in Osler-Weber-Rendu disease-a case report. Angiology 1987;38:484-8.

16 Whiting JH Jr, Morton KA, Datz FL, Patch GG, Miller FJ Jr. Embolisation of hepatic arteriovenous malformations using radiolabeled and nonradiolabeled polyvinyl alcohol sponge in a patient with hereditary hemorrhagic sponge in a patient with hereditary hemorrhagic
telangiectasia: case report. $\mathcal{F}$ Nucl Med 1992;33:260-2. 